\title{
Institutional Perspectives on Operationalising Climate Adaptation through Planning
}

\author{
Tony Matthews \\ Urban Research Program \\ Griffith University, Nathan \\ 170 Kessels Road \\ QLD 4111, Australia \\ Email: t.matthews@griffith.edu.au
}

\begin{abstract}
Adaptation to climate change is an imperative and an institutional challenge. This paper argues that the operationalisation of climate adaptation is a crucial element of a comprehensive response to the impacts of climate change on human settlements, including major cities and metropolitan areas. In this instance, the operationalisation of climate adaptation refers to climate adaptation becoming institutionally codified and implemented through planning policies and objectives, making it a central tenet of planning governance. This paper has three key purposes. First, it develops conceptual understandings of climate adaptation as an institutional challenge. Second, it identifies the intersection of this problem with planning and examines how planning regimes, as institutions, can better manage stress created by climate change impacts in human settlements. Third, it reports empirical findings focused on how the metro-regional planning regime in Southeast Queensland (SEQ), Australia, has institutionally responded to the challenge of operationalising climate adaptation. Drawing on key social scientific theories of institutionalism, it is argued that the success or failure of the SEQ planning regime's response to the imperative of climate adaptation is contingent on its ability to undergo institutional change. It is further argued that a capacity for institutional change is heavily conditioned by the influence of internal and external pathways and barriers to change which facilitate or hinder change processes. The paper concludes that the SEQ metro-regional planning regime has undergone some institutional change but has not yet undergone change sufficient to fully operationalise climate adaptation as a central tenet of planning governance in the region.
\end{abstract}

Keywords: Adaptation; Institutions; Institutional Change; Storylines; Southeast Queensland

\section{Introduction}

Climate change presents a real and immediate global threat. Early manifestations can be observed through climate shifts already occurring (IPCC 2007; Steffen, 2009; Stern, 2006). Notwithstanding ongoing scepticism and counter-theory, the majority of peer-reviewed climate science demonstrates that human activity is largely responsible for many ongoing changes to climate regimes globally and that the consequences of these changes will be severe (CSIRO, 2012; IPCC, 2007; Stern, 2006). Anthropogenic gases created by human activity have been building up in the atmosphere since the Industrial Revolution. Consequently, even the most strident efforts towards mitigation cannot fully diminish climate impacts which have become locked in by a century and a half of human development underpinned by industrialisation and heavy reliance on fossil fuels (Garnaut, 2008; Stern, 2006). Climate change adaptation is therefore an imperative must become a key climate change management tool. Climate adaptation in cities and metropolitan areas will be especially vital as the majority of the world's 
population is now urbanised (UN, 2009). Climate adaptation is understood as a process of engaging in direct action to limit and manage negative climate change impacts (Adger, Arnell and Tompkins, 2005; IPCC, 2007). It involves the development and delivery of strategies and interventions to adjust human and natural systems in order to moderate harm or gain from beneficial opportunities (Parry et al, 2007). Climate adaptation is a crucial strategy for responding to threats posed by climate change to human settlements. The nature and scale of specific climate impacts, along with the spatial form and function of affected settlements will significantly influence the type of adaptation strategies developed and operationalised. This paper applies the argument that successful climate adaptation strategies will reduce vulnerability to climate change impacts (Schipper, 2007). It argues that adaptation must be adequately operationalised in order to reduce climate change related vulnerabilities in human settlements. Planning regimes, as central institutions in directing and managing human settlements, have a vital function in delivering climate adaptation interventions (Gleeson, 2008; Wilson and Piper, 2010). Accordingly, the operationalisation of climate adaptation as a key issue of planning governance is crucial. This paper defines the operationalisation of climate change adaptation as referring to climate adaptation becoming codified and implemented as a key principle of planning governance and practice.

This paper reports emergent findings from an empirical inquiry focused on Southeast Queensland (SEQ), a rapidly growing metropolitan region that is identified as extremely vulnerable to climate change impacts (Hennessey et al, 2007). It adds to scholarly debates concerned with institutional accommodation of sustainability and climate change management, including the work of Connor and Dovers (2002, 2004); Dovers and Hezri (2010); Steele (2011); Steele and Gleeson (2010); and Young $(2002,2010)$. This paper examines how climate change adaptation has been operationalised by the SEQ metro-regional planning regime through institutional processes and change. The influence of pathways and barriers to associated institutional change is detailed and critically examined within this context. These issues are explored through reference to recent policy developments in SEQ, with specific focus on institutional responses to climate adaptation as enunciated and operationalised through the SEQ metro-regional planning regime. This paper develops conceptual understandings of climate change adaptation as an institutional challenge for planning regimes seeking to better manage the challenges and stresses created by climate change impacts. It analyses the nature and character of institutions as social entities and advance understandings of the institutional nature of planning regimes. It argues that the success of planning regimes operationalising climate change adaptation will be significantly conditioned by their capacity to more fully implement adaptation as a feature of governance through institutional change. The capacity and scope for institutional change is understood to be conditioned by the influence of internal and external pathways and barriers, which can facilitate or block institutional change processes. The 'storylines' concept advanced by Hajer $(1993,1995)$ is used to examine how dominant institutional narratives can shape institutional responses. Path dependence, a concept describing how institutions can resist change due to an embedded focus on particular issues, is examined as a barrier to institutional change in this paper. The new institutional frame of planning 'in' climate change (Steele and Gleeson, 2010), which views climate change as a current agenda for planning with multiple and ongoing implications, is characterised as a potential pathway to change. The storylines concept is applied to these ideas and linked to the issue of operationalising climate adaptation as a central tenet of planning governance through institutional processes.

The research process began in 2010 and examined statutory plans, policy documents, information papers, position papers, government circulars, minutes of planning committee meetings and parliamentary records. Over 130 separate documents and records were examined. This facilitated the development of both a chronological and thematic historiography of the ways in which climate change adaptation was addressed and operationalised by the SEQ metro-regional planning regime through the enunciation of statutory planning policy and 
regulation. Key institutional storylines were identified and subsequently tested and contextualised through interviews with planners, politicians, former ministers, non-government actors and consultants, all of whom have or had direct involvement in SEQ metro-regional planning regime. This two-step research process facilitated a systematic identification of the particular storylines that conditioned institutional responses and provided valuable findings in respect of how certain storylines facilitated or hindered institutional responses to climate adaptation through metro-regional planning in SEQ.

\section{Institutional Processes, Change and Planning as an Institution}

An understanding of how institutions identify, recognise and respond to stressors is essential to better understand adaptive responses to climate change. The nature and character of institutions as social scientific objects has generated much scholarly discussion. The task of fully defining and characterising institutions continues to yield opinion, counter-opinion and critique within scholarly literature (Hodgson, 2006; Kingston and Caballero, 2009; March and Olsen, 1989). Many definitions have been advanced, though North's (1990) definition is amongst the most heavily cited in recent literature (Kingston and Caballero, 2009). North defines institutions as the "humanely devised constraints that shape human interaction" (1990, p. 3). North views institutions as social entities that exist to reduce uncertainty and provide clarity to structure and enable social engagement. Building on this view, institutions may be described as "the fundamental building blocks of social systems" by providing a "generalised regulatory framework for socially acceptable behaviour" (Connor and Dovers, 2002, p. 7). In short, institutions govern through the development and imposition of social constraints that function throughout and across societies. Institutions are made up of formal and informal constraints. Formal constraints include laws, policies, constitutions and rules, whilst informal constraints can include less rigid social or group conventions, as well as accepted norms of behaviour (North, 1990). These can exist independently of as part of multiple or hierarchical sets. A simple example concerns institutional constraints designed to manage the behaviour of car drivers (Connor and Dovers, 2002). A single constraint may be that all drivers must possess a licence, multiple constraints may state that a driver must also have adequate insurance, whilst hierarchical constraints may state that a driver can only obtain a licence and insurance if they first submit to driver behaviour classes and undergo structured testing to ensure they are competent to drive on public roads.

A key characteristic of institutions is their capacity to react positively or negatively to particular stimuli through institutional change (Cortell and Peterson, 1999; Matthews 2012). Institutional change processes take place when an institution adds, removes or changes some or all of the social constraints it is responsible for. This tends to occur when an institution seeks to utilise new constraints that are intended to deliver improved social outcomes relative to the stimulus that originally prompted the change process (Alexander, 2005; Kingston and Caballero, 2009). When faced with a change imperative, an institution will likely face pathways and barriers that will facilitate or hinder change processes. Institutional responses will condition the nature of associated institutional change, as well as the success or failure of the change process. Institutions faced with compelling reasons to confront 'different problems' may find change processes especially problematic, particularly if the problems fall outside of those previously encountered or if institutional actions are strongly conditioned by path dependence (Low and Astle, 2009, p. 48). The demands created by different problems may encounter institutional resistance due to institutions becoming too used to dealing with common problems and struggling to comprehend and react to imperatives beyond the familiar. This is referred to as 'institutional arthritis' (Young, 2010) or 'institutional inertia' (Dovers and Hezri, 2010).

Planning regimes operating at any scale can be understood as institutions since the practice of planning involves the coordination of development activities within the scope of various social constraints (Alexander, 2005). As Healey et al (1999, p. 31) note, planning is "a set of 
governance practices for developing and implementing strategies, plans, policies and projects and for regulating the location, timing and form of development." Planning regimes therefore act to regulate development activities within pre-determined constraints designed to direct actors in specific ways. The social outcomes sought within this context relate to the institutional governance of spatial and land-use development. A central institutional challenge faced by planning regimes is the task of trying to balance the development aims of specific individuals and groups with broader social needs, including environmental protection, the provision of amenity, delivery of social services, infrastructure, public space, aesthetics, liveability, etc (Faludi, 2000). Planning regimes must be able to utilise existing institutional arrangements and accommodate new arrangements in order to discharge these obligations, both in times of institutional stability and in times of change and uncertainty (Forester, 1989).

\section{How Pathways and Barriers Condition Institutional Change}

Institutional change happens when an institution imposes new social constraints or alters existing ones in order to better manage the stresses created by a change imperative (Kingston and Caballero, 2009; North, 1990; Young, 2010). A process of institutional change includes a number of important steps, including recognising, characterising and accepting the change imperative and responding to the imperative (Dovers and Hezri, 2010). Institutional change can occur in response to various stimuli including existing or nascent social phenomena (Fünfgeld, 2010; Moser and Ekstrom, 2010), political objectives (Kantor, 1998), the influence of lobby groups (Liebcap, 1989); collective bargaining (Alston, 1996); resource depletion (Ostrom, 2005); and emerging environmental imperatives (Connor and Dovers, 2002, 2004; Young, 2010). Operationalising climate adaptation as a central tenet of planning governance corresponds to the latter category and can be understood in terms of improved collective and social outcomes if the results of institutional change processes reduce climate vulnerability and increase resilience in human settlements.

The conceptual model of 'storylines' presented by Hajer $(1993,1995)$ is widely regarded in scholarship as a means for understanding the influence of pathways and barriers in conditioning institutional change. Hajer characterises storylines as social narratives "through which elements from many different domains are combined and that provide actors with a set of symbolic references that suggest a common understanding" $(1995$, p. 62). They can fulfil an essential role in directing institutional discourse by clustering knowledge and positioning actors. Groups of actors who subscribe to particular storylines may form 'discourse coalitions', which are characterised by collections of storylines, the actors who subscribe to them and the institutional practices through which elements of associated social narratives are espoused (1995, p. 65). Hajer $(1993,1995)$ developed the storylines concept to test how particular narratives acted as pathways or barriers to institutional change in respect of the emergence of ecological modernisation as an environmental language used to address the acid rain phenomenon in the UK and Netherlands. The analyses show that storylines can facilitate or hinder institutional change processes by discursively framing specific issues and establishing them as compelling institutional narratives. Hajer's discoveries demonstrate that new institutional imperatives can be blocked or advanced by particular storylines if the storylines gain sufficient traction to influence institutional decision making. In this regard, particular storylines can themselves function as pathways or barriers to institutional change.

The concept of path dependence refers to situations where institutions resist change because of an established and embedded focus on a specific set of issues (Cortell and Peterson, 1999; David, 1985; Low and Astle, 2009). Path dependence can act as a strong barrier to institutional change. When path dependence occurs, institutions lack capacity for alternative thinking and decision making, even when confronted by emerging imperatives. As Low and Astle note, path dependency can create situations where "institutions that have grown up around one sort of problem may be unable to respond adequately when confronted by a quite different sort of 
problem" (2009, p. 48). Applying this to the storylines concept, path dependency can be understood to hinder the institutionalisation of new storylines because established institutional storylines may have created path dependency and so inhibit the institutionalisation of new narratives reflecting shifting social circumstances. In such cases, institutional change may be slow or unsuccessful or be completely blocked, due to ongoing path dependence eventually leading to institutional inertia. Low and Astle (2009) explored the concept of path dependency to examine the evolution of institutional governance within the transport systems of Melbourne, Australia. They concluded that path dependence ensured a preference for road building within Melbourne's transport institutions. Consequently, storylines concerned with the need for improved public transport options were not sufficiently compelling to enable institutional change.

An institutional frame, referred to as planning 'in' climate change, offers a potential pathway towards institutional change in the context of emerging environmental imperatives (Steele and Gleeson, 2010). Planning 'in' climate change is proposed as a new model of institutional thinking within planning regimes. Under this frame, planning regimes recognise the immediacy of climate change as a lived institutional challenge with multiple and ongoing implications. Responses occur decisively and quickly through institutional change, the imposition of new rules of governance and the recognition of climate change management as a core planning agenda which exists as a meta-theme and drives new curriculum and professional development within the planning sphere. In the context of planning 'in' climate change, the immediate threat of climate change is understood as inherently linked to the full spectrum of planning praxis, leading to a "rich diversity of planning theory/practice for action and change [and a] focus on transformational learning and change" (Steele and Gleeson, 2012, p. 115). The authors argue that current institutional understandings of climate change within planning are generally located outside the planning 'in' climate change frame. Instead they are situated in either the planning 'about' climate change frame or, more commonly, the planning 'for' climate change frame. Planning 'about' climate change understands the phenomenon as a threat but sees it as a distant problem for planning. It is characterised by a relational dimension that regards climate change as a real but still distant agenda that represents just one part of a wider suite of planning interest and activity. Within the context of planning 'for' climate change, climate change is institutionally viewed as one of many planning challenges that may require attention in the short-term, but is unlikely to warrant significant strategic action. It leads to a policy agenda focused on developing policies and planning tools to manage climate change impacts, but falls short of developing clear strategies to operationalise and implement strategies. Storylines associated with the planning 'for' climate change may not compel urgent institutional change. The planning 'in' climate change frame may however, as storylines supporting institutional change in respect of operationalising climate adaptation gain traction in planning institutions, who in turn become more willing to recognise adaptation as an immediate and compelling planning imperative.

\section{Climate Adaptation as an Imperative for Planning}

Scholars increasingly argue climate change represents an unprecedented challenge for planning and that a key goal for planning regimes must be the comprehensive integration of climate adaptation management policies and strategies into planning governance (Gleeson, 2007, 2008; Matthews, 2011, 2012; Newman, Beatley and Boyer, 2009; Smith et al, 2010; Wilson and Piper, 2010). Gleeson identifies the urgency of climate adaptation in an urban context, stating that, "the imminence, scale and speed of climate change threats seem to overwhelm the principal mitigation strategies on offer" (2007, p. 1). He argues for a policy-led response from planning, stating that, "planning must look to steer change, mould it, in search of urban resilience. The resilient city is the goal: the interplay of evolution and adaptation (policy) will shape its restless form" (2007, p. 6). Planning may pursue a policy basis in respect of mitigation also. This may occur through increasing densities; promoting the integration of residential areas, employment 
services and public transport; minimising car dependence; and prioritising design standards that are sensitive to local climate conditions. However, the built environment is very slow to change and new building stock and infrastructure is designed to last several decades or more. Mitigation through manipulation of the built environment therefore challenges the scope of meaningful planning response relative to adaptation, as substantive change will take many years to yield useful returns through reduced carbon emissions. This paper does not suggest that planning should ignore the necessity for mitigation, but rather argues that the operationalisation of adaptation is an equally necessary and immediate planning imperative, given the immediacy of the emerging climate threat and an acknowledgement that planning is now taking place 'in' climate change.

Climate adaptation falls within the scope of planning as it can be implemented locally, quickly and with the use of existing planning tools such as zoning, design and coordination and delivery of services and utilities (Gleeson, 2007; Matthews, 2011). Planning regimes that recognise climate adaptation as an immediate institutional challenge and respond through change and the development of new policies may go on to impose constraints to increase the adaptive capacity of both new and existing development. These activities may be directed in several ways. One is to coordinate the preparation of location-specific adaptation plans focused on delivering adaptive interventions (Wilson and Piper, 2010). These plans can direct new development and re-development in specific ways to ensure that spatial, land-use and infrastructural interventions have in-built adaptive capacity. Planning regimes can also build adaptive responses directly into local development frameworks and plans, along with specific implementation and monitoring strategies (Matthews, 2011; Wilson and Piper, 2010). Designled adaptation can be facilitated in the same way, with adaptive design and materials codified in plans and policies and delivered through development assessment and urban design standards (Matthews, 2011). However, it is unlikely that these steps will be taken if planning regimes resist institutional change or fail to acknowledge that climate change is a current threat, rather than a distant problem.

The task of addressing climate adaptation through planning therefore becomes an institutional challenge (Dovers and Hezri, 2010). New or emerging challenges faced by planning regimes can often be at odds with existing institutional arrangements, creating a need for institutional change (Alden, Albrechts and da Rosa Pires, 2001; Alexander, 2005). Changes of this nature can significantly challenge vested interests and lead to significant contention within planning regimes and wider political and social structures. This may lead to an absence of adequate political, policy, financial and professional support. Central and local government, developers, the public and other professions may either embrace or reject the need for adaptation. Planning regimes may struggle to develop and implement meaningful adaptive measures in the absence of ideological and financial support (Matthews 2011). This paper suports the view that anticipatory adaptation can lead to better results and that a 'wait and see' approach (Wilson, 2006). Failing to address anticipatory adaptation may ultimately prove more damaging and costly, even in the context of potential uncertainties around the extent, timing and ultimate costs of planning-led adaptation.

Addressing climate change adaptation will only be adequately managed by planning regimes prepared to undergo institutional change processes in order to better respond to it as a new imperative. Planning regimes that resist institutional change are unlikely to effectively manage climate change impacts through adaptation. Planning regimes that recognise this need and respond through institutional change can operationalise climate adaptation through planning policy and practice and ensure that locally appropriate climate adaptation strategies become codified and implemented as part of everyday planning activity. The extent, degree and scale of change faced by any planning regime trying to respond to the challenge of climate adaptation will depend in part on the nature and severity of climate change impacts faced by the country, region or city to which the regime is responsible. However, severe impacts alone are not always 
enough to lead to institutional change. Also of significant influence are pathways and barriers to change. These can significantly condition institutional responses to change imperatives, not least to the imperative of climate adaptation.

\section{Findings from Southeast Queensland (SEQ)}

The remainder of this paper presents findings from an empirical inquiry focused on Southeast Queensland (SEQ). The concepts of path dependency and planning 'in' climate change are applied to the storylines model and used to illuminate the manner in which climate adaptation has been enunciated and operationalised through policies and objectives guiding the metroregional planning regime in Australia's fastest growing region. Southeast Queensland (SEQ) is a heavily urbanised and rapidly expanding metropolitan region on Australia's east coast. The SEQ metropolitan region forms a long coastal conurbation, running 200 kilometres from Noosa in the north to Coolangatta in the south. A second major conurbation runs from the coast, via Brisbane, to the city of Toowoomba in the west. The current population of the SEQ region is 2.7 million people, a figure predicted to increase to 4.4 million by 2031 (DIP, 2009a, p. 8). Two of Australia's largest cities, Brisbane and Gold Coast City, are in SEQ. They are respectively third and sixth largest nationally. The Intergovernmental Panel on Climate Change (IPCC) highlights SEQ as a climate change "vulnerability hotspot" in Australia (Hennessy et al, 2007, p. 525). Climate change impacts predicted to face SEQ over the coming century include increased inundation, inland storm surges, reduced water availability, sea level rises up to $0.79 \mathrm{~m}$ and an increase in the frequency of days where temperatures exceed $35^{\circ} \mathrm{C}$. Notwithstanding these predicted impacts, SEQ is already subject to natural hazards and severe weather events including bushfires, coastal storm surges and inland flooding. Existing regional challenges will be exacerbated by future climate change impacts and will lead to significant stress for human settlements. Climate adaptation is therefore an imperative for human settlements throughout SEQ.

Policy and regulatory provisions guiding planning activity in SEQ are established at the metroregional scale. The metro-regional planning regime operates as on a statutory basis but utilises the direct involvement of state and local government in decision making and the setting of planning policies. The current statutory arrangement evolved from an earlier collaborative model that was developed throughout the 1990s and into the early 2000s, which sought to use a partnership model between state and local governments to develop planning and growth management frameworks for the entire SEQ region. The current statutory system came into force in 2004 with the joint support of state and local governments (Abbott, 2009). Regular meetings, held every two months under the auspices of the SEQ Regional Planning Committee (RPC), bring together a cross-section of stakeholders to discuss on-going and emerging planning issues. This ensures that local and state government representatives, along with other nominated stakeholders, have the opportunity to discuss regional planning issues on a regular basis and can establish common positions to address these through the statutory planning system. Institutional storylines may be created, altered or dismissed at these meetings. This collaborative model has evolved over 20 years and has successfully addressed many regional planning challenges in SEQ (Abbott, 2009; Dodson, 2009). As such, current institutional arrangements have considerable in-built capacity and experience of dealing with large regional challenges and so should be reasonably well placed to address climate adaptation as an emerging and serious planning issue.

Current regional planning policies are expressed through the Southeast Queensland Regional Plan (SEQRP) 2009-2031. The SEQRP has statutory force and primacy over all other planning policy documents in the region. All planning interventions, activities and strategies carried out by any of SEQ's 11 local councils must be compatible with policies and objectives expressed in the regional plan (DIP, 2009a). Consequently, the SEQRP has significant institutional status over all other planning instruments in the region. The SEQRP is designed to provide an 
institutional and governance framework for strategically managing spatial development and growth on a metropolitan scale. Its function is to "manage regional growth and change in the most sustainable way to protect and enhance quality of life in the region" (DIP, 2009a, p. 4). The SEQRP is reviewed every 4 years and an updated plan is produced to reflect changing circumstances and institutional priorities within the regional planning regime. The current SEQRP also has a complementary plan for managing climate change, entitled the Draft Southeast Queensland Climate Change Management Plan (DCCMP) 2009-2031. It addresses both adaptation and mitigation. The plan states that "urban and regional planning has a key role in building resilience to natural hazards and climate change by guiding patterns of development and infrastructure to...offer greater protection from impacts such as coastal inundation, flooding, landslide or bushfires" (DIP, 2009b, p. 4). Together these plans document the institutional and policy preferences of the SEQ metro-regional planning regime in respect of a suite of planning issues, including climate change and climate adaptation.

Climate adaptation features amongst planning policies and objectives in the SEQRP and DCCMP. The SEQRP directs that planning should "increase the resilience of communities, development, essential infrastructure, natural environments and economic sectors to natural hazards including the projected effects of climate change" (DIP, 2009a, p. 44). It states that planning can reduce risks from projected climate change effects in SEQ "by establishing adaptation strategies to minimize vulnerability" (DIP, 2009a, p. 44). The plan also prioritises the avoidance of development in hazardous areas, improving the design of developments to make them more suited to varied climatic conditions and improving community and infrastructure resilience. Policies 1.4.1 - 1.4.3 in the SEQRP call for the establishment of adaptation strategies to "minimise vulnerability to riverine flooding, storm tide or sea level inundation, coastal erosion, bushfires and landslides...storm surges, heatwaves and high temperatures, reduced and more variable rainfall, cyclones and severe winds, and severe storms and hail" (DIP, 2009a, p. 44). The DCCMP 2009 also confirms the necessity of climate adaptation. It proposes 13 draft actions to increase adaptive capacity across the region (DIP, 2009b, p. 14, 30-35). Four were acknowledged as already underway in 2009, when the plan was released. These include preparing a new coastal plan (Draft Action 20); implementing the policies of the coastal plan across the region (Draft Action 22); acquiring digital elevation data for coastal areas (Draft Action 23) and developing a regional summary of projected climate change impacts for SEQ (Draft Action 27). Whilst an institutional acknowledgement of climate adaptation as an issue requiring planning response is laudable, there remains a lack of specific operational guidance to direct planning activity at the local scale in the context of any of the specific vulnerabilities identified above. This suggests that while limited institutional change took place within the planning regime and that adaptation was recognised as a planning challenge, the scope of change was not sufficient to fully operationalise climate adaptation and centre it within planning governance.

The limited extent of institutional change within the SEQ metro-regional planning regime appears to indicate elements of path dependency. Current institutional storylines, as expressed through policy and provisions in the SEQRP and DCCMP, indicate an institutional framework focused on planning 'for' climate change. This was tested through interview and many respondents stated that whilst climate adaptation is noted as one institutional agenda amongst many, it is not viewed a singular imperative. Interviewing further confirmed that there is limited enthusiasm for allowing SEQ's local councils to develop and implement locally appropriate planning strategies and interventions due to the complexities of cross-jurisdictional action and funding conflicts across or within levels of government. One respondent offered a particularly interesting insight, suggesting that the priority was to be seen to do something by preparing a climate change management plan, rather than actually implementing the policies set out by either that plan or the main regional plan. This corresponds to the planning 'for' climate change institutional frame, rather than the planning 'in' climate change frame (Steele and Gleeson, 2010). It also suggests disconnect between the clear scientific predictions of 
future climate change impacts in SEQ and related planning responses. The influence of path dependency in framing institutional perspectives may partly explain this situation. In the SEQ case, path dependency seems to stem from a long-standing institutional perspective that views planning as best used to manage urban growth and population, as well as to deliver large infrastructure projects (Dodson, 2009; Minnery and Low Choy, 2010). This represents a dominant storyline that has long been institutionally espoused through planning in SEQ. Both Labor and the Liberal National Party (LNP), the state's major political parties, subscribe to this storyline. This dominance of this storyline was also confirmed through interviews informing this paper. Within this context, path dependency can be understood as a significant barrier to institutional change as it places far more focus on growth management than climate change management through adaptation.

Notwithstanding the current level of institutional elaboration of climate adaptation as a planning issue in SEQ, there remains potential and scope for improvement. The apparent barrier to change created by path dependency and an associated focus on planning 'for' climate change may yet give way to new pathways to change. A changed institutional environment could be characterised by planning 'in' climate change becoming the dominant institutional frame guiding the activities of metro-regional planning in SEQ. In this context, the operationalisation of adaptation would enjoy more meaningful institutional attention. Significant institutional change is generally conditioned by three factors. These are an external crisis or series of crisis moments, change-orientated preferences and institutional capacity (Cortell and Peterson, 1999; Hogan, 2006; Schmidt, 2010; Young, 2002, 2010). Recent environmental impacts in SEQ, including the drought that severely affected the region for many years and the major flooding of 2011, may be viewed as crisis moments with inherent transformative potential. The serious and region-wide impacts of these events on human settlements in SEQ have potential to create and sustain a level of institutional stress that cannot be easily ignored. These trigger events may create pathways to new institutional storylines founded in the planning 'in' climate change frame, where climate change is understood as an immediate institutional imperative that must be institutionally accommodated across the full spectrum of planning praxis. This idea was tested through interview. Most respondents broadly agreed with the view, though some suggested that more specific triggers would be required to compel substantial institutional change as the drought and floods could not be directly attributed to climate change. However, many were unable to offer suggestion as to what form such triggers may take. However, one respondent suggested that "a cyclone hitting SEQ might be sufficient" to compel institutional change as would be devastating to built and natural environments, disruptive, costly and most importantly, not attributable to climate variability as SEQ is sub-tropical and therefore not prone to cyclonic activity.

Trigger events alone are unlikely to be sufficient in compelling substantive institutional change in the SEQ metro-regional planning regime. Change-orientated preferences and institutional capacity must also be present. Change-orientated preferences describe how institutional actors can shape whether or not change occurs following a trigger event. Institutional actors may be internal or external and include politicians, policy officials and public stakeholders. Institutional capacity refers to the way in which an institutional actor's ability to direct change depends on their position within an institutional hierarchy. Institutional change processes can be frustrated in situations where actors fail or refuse to acknowledge the severity of a change dynamic and consequently block change. The existing focus on climate adaptation in the Southeast Queensland Regional Plan (SEQRP) 2009-2031 and the Draft Climate Change Management Plan (DCCMP) 2009-2031 indicates that institutional change took place within the metro-regional regime. If institutional change occurred once, there is a potential for it to happen again, particularly in the context of recent trigger events. However, these regional plans are a product of a Labour government and senior policy officials in Queensland and demonstrate that influential institutional actors recognised the necessity of placing climate adaptation within a framework of planning governance when preparing the plans. There was a 
state election in Queensland in March 2012 and Labor lost office to the Liberal National Party (LNP). It is difficult to predict what actions, if any, the LNP state government will take in respect of climate adaptation. Recent LNP policy on climate change supported a focus on climate adaptation as an institutional issue and specifically highlighted the importance of on-going research into developing appropriate adaptation strategies for the state (LNP, 2010). However, some of the first actions undertaken by the LNP government included the cancellation of numerous existing climate change management programs and policies across the state and a significant dilution of a suite of environmental legislation on the basis that they impede growth. The Queensland Office of Climate Change was also wound down. This suggests that the LNP government is firmly focused on the dominant storyline that characterises planning as primarily a vehicle for managing urban growth and population and deliver large infrastructure projects. It now remains to be seen whether future regional plans in SEQ will offer any policy basis in respect of climate change and climate adaptation.

A more positive indication of a move towards operationalising climate adaptation as a main tenet of planning governance in SEQ is evidenced through the establishment of the Southeast Queensland Climate Adaptation Research Initiative (SEQ-CARI). The project is part of the Commonwealth Scientific and Industrial Research Organisation's (CSIRO) Adaptation Flagship. The CSIRO is Australia's national science and research agency and its adaptation flagship program is charged with delivering scientific solutions to protect Australia's national interests in a context of global climate change. The SEQ-CARI project is designed to examine climate vulnerabilities in the SEQ region and to develop cost-effective adaptation strategies for different sectors (DIP, 2009b). The SEQ-CARI project includes a targeted stream designed to assess adaptation options related to planning in SEQ. The findings and recommendations of the project may provide a compelling rationale to support institutional change within the SEQ metro-regional planning regime, particularly if operationalising climate adaptation within planning is shown to be cost-effective. A process of institutional change that is conditioned by recent trigger events and supported by an economic rationale emerging from SEQ-CARI may create storylines that acts as pathways towards the institutionalisation of the planning 'in' climate change frame and an associated focus on the operationalisation of climate adaptation within the SEQ metro-regional planning regime.

As a final point, it is important to note that the pathways and barriers discussed in this section are unlikely to be the only ones influencing the institutional orientation of the SEQ metroregional planning regime over the coming years. Whether anticipated or not, other pathways and barriers will almost certainly emerge, most likely in the context of specific trigger events. Though not an exhaustive list, this paper identifies five potential pathways that could emerge in time, leading to a fuller operationalisation of climate adaptation. These are the emergence of new public discourses which demand institutional responses to climate adaptation through planning; the emergence of bold new political leadership; internal institutional pressure within the planning regime where key actors and decision makers begin to compel climate adaptation as a planning storyline; increased funding for adaptation action and a growth in influential storylines advocated by external actors and stakeholders who participate in the planning process at regional or local level. Potential barriers could also emerge. These may include structural changes to the SEQ planning regime which reduce its scope for integrating new forms of governance across the region; the growth of storylines which reject climate adaptation as a planning issue; the emergence of new political and social actors who reject climate change science and a decline in funding for research into the role of planning as a vehicle for delivering adaptive responses. It is probable that some or all of these pathways and barriers will emerge over time. When they do, they will exert varying degrees of influence on the institutional orientation of SEQ metro-regional planning regime and will almost certainly condition the extent and nature of institutional change processes. While the consequential effects on the operationalisation of climate adaptation as a central tenet of planning governance are not easily 
predicted at this time, it is certain that each of these pathways and barriers possesses capacity to challenge existing institutional structures in SEQ.

\section{Conclusion}

This paper has examined the institutional role of planning in addressing climate adaptation and has explored how planning regimes may institutionally operationalise climate adaptation as a central tenet of planning governance. In doing so it has added to nascent understandings of how planning can operationalise climate adaptation as part of wider efforts to institutionally accommodate climate change. How the imperative of climate adaptation is treated in an institutional context of planning will be conditioned by capacity for institutional change within specific planning regimes. This capacity for change will in turn be directed by particular change imperatives, the role of institutional actors and the influence both internal and external pathways and barriers to change. Climate adaptation will be operationalised most effectively by institutions that are open to change and responsive to emerging change imperatives. Institutions characterised by strong path dependency or inertia will likely struggle to respond to climate adaptation as a compelling institutional issue. Additionally, dominant institutional storylines will exert significant influence on any institution's capacity to change and may help or hinder change processes.

This paper characterised the operationalisation of climate change adaptation as referring to climate adaptation becoming codified and implemented as a key principle of planning governance and practice. It has shown that some institutional capacity for recognising climate adaptation as a planning challenge exists in SEQ. Climate adaptation is established as an institutional issue in the Southeast Queensland (SEQ) metro-regional planning regime through its enunciation in planning policy in the Southeast Queensland Regional Plan (SEQRP) 2009-2031 and the Draft Southeast Queensland Climate Change Management Plan (DCCMP) 2009-2031. The fact that climate adaptation has a policy basis in both the SEQRP and DCCMP show that some institutional change, led by an understanding of the need to address climate adaptation through planning, took place within the regime. However, these policies lack operational guidance, particularly in terms of purposefully directing the region's local councils in terms of how they can implement locally appropriate adaptive interventions. A fuller institutional operationalisation of climate adaptation appears to be blocked by elements of path dependency within the metro-regional planning regime. In particular, institutional and political storylines appear focused on a dominant view of planning as a means of managing growth and delivering large infrastructure. Storylines also appear focused on the planning 'for' climate change institutional frame, rather than the planning 'in' climate change frame. This is evidenced by the findings of research supporting this paper, which demonstrated that climate adaptation is noted as just one institutional agenda amongst many in SEQ metro-regional planning.

Climate change represents a new set of challenges for planning. The phenomenon will impact worldwide, leading to escalating social stress in many cases. Human settlements, including major cities and metropolitan areas, will experience significant vulnerability to climate change impacts. Planning is becoming a vital discipline in preparing for and managing these impacts. Within this context, climate adaptation is a profound new challenge for planning theory and practice. Planning will need to adjust to shifting circumstances and priorities and is likely to encounter new requirements, boundaries and limitations. Many of these will require new approaches and thinking, potentially including an ideological and institutional shift towards the planning 'in' climate change frame. The ways in which planning approaches these challenges will significantly condition the capacity of human settlements to address the emerging challenge of climate change over coming decades and beyond. On that basis, the case study of the SEQ metro-regional planning regime presented in this paper adds to the growing knowledge base concerned with addressing the climate adaptation imperative through planning scholarship and praxis. 


\section{References}

Abbott, J. (2009) Planning for complex metropolitan regions: a better future or a more certain one?, Journal of Planning Education and Research, 28, pp. 503-517.

Adger, W.N., Arnell, N.W. and Tompkins, E.L. (2005) Successful adaptation to climate change across scales, Global Environmental Change, 15, pp. 77-86.

Alden, J. Albrechts, L. and da Rosa Pires, A. (2001) In search of new approaches for planning, in: Albrechts, L., Alden, J. and da Rosa Pires, A. (Eds) The Changing Institutional Landscape of Planning (Aldershot, Ashgate).

Alexander, E. R. (2005) Institutional transformation and planning: from institutionalization theory to institutional design, Planning Theory, 4(3), pp. 209-222.

Alston, L. (1996) Empirical work in institutional economics: an overview, in: Alston, L., Eggertsson, T. and North, D. (Eds) Empirical Studies in Institutional Change, pp. 25-30 (Cambridge, Cambridge University Press).

Connor, R. D. and Dovers, S. R. (2002) Institutional Change and Learning for Sustainable Development Working Paper 2002/1 (Canberra, Centre for Resource and Environmental Studies, ANU).

Connor, R. D. and Dovers, S. R. (2004) Institutional Change for Sustainable Development (Cheltenham, Edward Elgar).

Cortell, A. P. and Peterson, S. (1999) Altered states: explaining domestic institutional change, British Journal of Political Science, 29, pp. 177-203.

CSIRO [Commonwealth Scientific and Industrial Research Organisation] (2012) State of the Climate Report 2012, (Melbourne, Commonwealth Scientific and Industrial Research Organisation).

David, P. (1985) Clio and the economics of QWERTY, American Economic Review 75, pp. 332-337.

DIP [Department of Infrastructure and Planning] (2009a) South East Queensland Regional Plan 2009-2031 (Brisbane, Queensland Government).

DIP [Department of Infrastructure and Planning] (2009b) Draft South East Queensland Climate Change Management Plan 2009-203. (Brisbane: Queensland Government).

Dodson, J. (2009) The infrastructural turn in Australian spatial planning, International Planning Studies, 14(2), pp. 109-123.

Dovers, S. and Hezri, A. (2010) Institutions and policy processes: the means to the ends of adaptation. Wiley Interdisciplinary Reviews: Climate Change, 1, pp. 212-231.

Faludi, A. (2000) The performance of spatial planning, Planning Practice and Research, 15(4), pp. 299-318.

Forester, J. (1989) Planning in the Face of Power (California, University of California Press).

Garnaut, R. (2008) Garnaut Climate Change Review: Report to the Commonwealth, State and Territory Governments of Australia (Port Melbourne, Cambridge University Press).

Gleeson, B. (2007) The Endangered State of Australian Cities: Climate Threat and Urban Response Griffith University Urban Research Program Issues Paper 8 (Brisbane, Urban Research Program).

Gleeson, B. (2008) Waking from the dream: an Australian perspective on urban resilience, Urban Studies, 45, pp. 2653-2668.

Hajer, M. (1993) Discourse coalitions and the institutionalisation of practice: the case of acid rain in Great Britain, in: Fischer, F. and Forester, J. (Eds) The Argumentative Turn in Policy Analysis and Planning (London, Routledge).

Hajer, M. (1995) The Politics of Environmental Discourse, Environmental Modernisation and the Policy Process (Oxford, Clarendon Press).

Healey, P., Khakee, A., Motte, A. and Needham, B. (1999) European Developments in Strategic Spatial Planning, European Planning Studies, 7(3), pp. 339-355.

Hennessy, K., et al. (2007) Australia and New Zealand, in: Parry et al. (Eds) Climate Change 2007: Impacts, Adaptation and Vulnerability. Contribution of Working Group II to the Fourth Assessment Report of the Intergovernmental Panel on Climate Change (Cambridge, Cambridge University Press).

Hodgson, G. M. (2006) What are institutions? Journal of Economic Issues, 40(1), pp. 1-25.

Hogan, J. (2006) Remoulding the critical junctures approach, Canadian Journal of Political Science, 39, pp. 657-679.

Fünfgeld, H. (2010) Institutional challenges to climate risk management in cities, Current Opinion in Environmental Sustainability, 2, pp. 156-160.

IPCC (2007) Summary for policymakers, in: Parry, M.L., et al, (Eds) Climate Change 2007: Impacts, Adaptation and Vulnerability. Contribution of Working Group II to the Fourth Assessment Report of the Intergovernmental Panel on Climate Change (Cambridge: Cambridge University Press). 
Kantor, S. E. (1998) Politics and property rights: the closing of the open range in the postbellum south (Chicago, University of Chicago Press).

Kingston, C. and Caballero, G. (2009) Comparing theories of institutional change, Journal of Institutional Economics, 5, pp: 151-180.

Liebcap, G.D. (1989) Contracting for Property Rights (Cambridge, Cambridge University Press).

LNP [Liberal National Party] (2010) Direct Action Plan on the Environment and Climate Change (Barton, Liberal Party)

Available at

http://liberal.org.au/ /media/Files/Policies\%20and\%20Media/Environment/The\%20Coalitions\%2 0Direct\%20Action\%20Plan\%20Policy.ashx (accessed February 2012).

Low, N. and Astle, R. (2009) Path dependence in urban transport: an institutional analysis of urban passenger transport in Melbourne, Australia, 1956-2006, Transport Policy, 16, pp. 47-58.

March, J. and Olsen, J. (1994) Institutional perspectives on political institutions, Governance, 9, pp. 247 264.

Matthews, T. (2011) Climate Change Adaptation in Urban Systems: Strategies for Planning Regimes (Brisbane, Urban Research Program).

Matthews, T. (2012) Responding to climate change as a transformative stressor through metro-regional planning. Local Environment: The International Journal of Justice and Sustainability, 17(10), pp. 10891103.

Minnery, J. and Low Choy, D. (2010) Early innovations and false starts, in: Gleeson, B. and Steele, W. (Eds) A Climate for Growth: Planning South-East Queensland (St. Lucia, UQP).

Moser, S. C. and Ekstrom, J. A. (2010) A framework to diagnose barriers to climate change adaptation, in: Proceedings of the National Academy of Sciences of the United States of America, 107(51), pp. 2202622031.

Newman, P., Beatley, T. and Boyer, H. (2009) Resilient Cities: Responding to Peak Oil and Climate Change, (London, Island Press).

North, D.C. (1990) Institutions, Institutional Change and Economic Performance (Cambridge, Cambridge University Press).

Ostrom, E. (2005) Understanding Institutional Diversity (New Jersey, Princeton University Press).

Parry, M.L., et al. (Eds.) 2007. Climate Change 2007: Impacts, Adaptation and Vulnerability. Contribution of Working Group II to the Fourth Assessment Report of the Intergovernmental Panel on Climate Change (Cambridge, Cambridge University Press).

Schipper, E.L.F. (2007) Climate Change Adaptation and Development: Exploring the Linkages (University of East Anglia, Tyndall Centre for Climate Change Research).

Schmidt, V.A. (2010) Taking ideas and discourse seriously: explaining change through discursive institutionalism as the fourth 'new institutionalism', European Political Science Review, 2(1), pp. 1-25.

Smith, I., Dodson, J., Gleeson, B. and Burton, P. (2010) Growing Adaptively: Responding to Climate Change through Regional Spatial Planning in England and Australia (Brisbane, Urban Research Program).

Steffen, W. (2009) Climate Change 2009: Faster Change and More Serious Risks (Canberra, Australian Government Department of Climate Change).

Steele, W. (2011) Strategy-making for sustainability - an institutional approach to transformative planning in practice, Planning Theory \& Practice, 12(2), pp. 205-221.

Steele, W. and Gleeson, B. 2010. Planning in climate change, in: Gleeson, B. and Steele, W. (Eds) A Climate for Growth: Planning South-East Queensland (St. Lucia, UQP).

Stern, N. 2006. Stern Review on The Economics of Climate Change (London: HM Treasury).

UN [United Nations] (2009) State of the World Population 2009 (New York, UNFPA).

Wilson, E. and Piper, J. (2010) Spatial Planning and Climate Change (London, Routledge).

Young, O. R. (2002) The Institutional Dimensions of Environmental Change: Fit, Interplay and Scale (Cambridge, MIT Press).

Young, O. R. (2010) Institutional dynamics: Resilience, vulnerability and adaptation in environmental and resource regimes, Global Environmental Change, 20, pp. 378-385. 
